\title{
Berberine mitigates methotrexate-induced oxidative stress and inflammation in the cerebrum of rats
}

\author{
Walaa G. Hozayen ${ }^{1,2}$, Shimaa M. Ramadan ${ }^{1}$, Abdulmannan Fadel ${ }^{3}$, Ayman M. Mahmoud ${ }^{4} *$ \\ ${ }^{1}$ Biochemistry Division, Chemistry Department, Faculty of Science, Beni-Suef University, Egypt. \\ ${ }^{2}$ Biotechnology and Life Sciences Department, Faculty of Postgraduate Studies for Advanced Sciences (PSAS), Beni-Suef University, Egypt. \\ ${ }^{3}$ School of Healthcare Science, Faculty of Science and Engineering, Manchester Metropolitan University, Manchester, United Kingdom. \\ ${ }^{4}$ Physiology Division, Department of Zoology, Faculty of Science, Beni-Suef University, Egypt.
}

\section{ARTICLE INFO}

Article history:

Received on: 14/09/2017

Accepted on: 22/10/2017

Available online: $30 / 11 / 2017$

Key words:

Methotrexate, Inflammation,

Berberine, Oxidative stress.

\begin{abstract}
Berberine is a natural isoquinoline alkaloid with multiple beneficial therapeutic effects. This study was designed to evaluate the protective effect of berberine against methotrexate (MTX)-induced oxidative stress and inflammation in the brain of rats. Rats received a single intraperitoneal injection of MTX $(20 \mathrm{mg} / \mathrm{kg})$ and orally administered $25 \mathrm{mg} / \mathrm{kg}$ and $50 \mathrm{mg} / \mathrm{kg}$ body weight berberine for 7 days. MTX-induced rats showed significantly increased lipid peroxidation and nitric oxide levels in the cerebrum. Treatment of the MTXinduced rats with berberine produced a significant decrease in cerebral levels of lipid peroxidation and nitric oxide. In addition, berberine induced a significant increase in reduced glutathione, superoxide dismutase, glutathione peroxidase and glutathione-S-transferase in the cerebrum of MTX-induced rats. Rats received MTX showed a significant up-regulation of nuclear factor-kappaB (NF- $\mathrm{BB})$, inducible nitric oxide synthase (iNOS), tumor necrosis factor alpha (TNF- $\alpha$ ) and interleukin-1beta (IL-1 $\beta)$ expression in the cerebrum, an effect that was significantly reversed following treatment with berberine. In conclusion, berberine protects against MTXinduced neurotoxicity through attenuating oxidative stress and inflammation, and boosting the antioxidant defenses.
\end{abstract}

\section{INTRODUCTION}

The dihydrofolate reductase inhibitor methotrexate (MTX) is an anti-metabolite used frequently to treat autoimmune diseases and as a chemotherapeutic agent against many types of cancer (Ayad et al., 2014, Sakthiswary and Suresh, 2014, Zhu et al., 2014). In the treatment of rheumatoid arthritis and psoriasis, MTX represents the favored steroid-sparing immunosuppressant (Roenigk et al., 1998). Acute, sub-acute, and long-term neurotoxicities of MTX have been well-established (Buizer et al., 2006; Inaba et al., 2008). Disruption of central nervous system (CNS) folate homeostasis and/or direct neuronal damage are the mechanisms through which MTX exerts neuro-toxicity (Cole

\footnotetext{
* Corresponding Author

Ayman M. Mahmoud, Physiology Division, Zoology Department, Faculty of Science, Beni-Suef University, Salah Salim St., 62514, Beni-Suef, Egypt.E-mail:ayman.mahmoud @ science.bsu.edu.eg
}

et al., 2009; Vezmar et al., 2009). Studies have demonstrated that subacute MTX neurotoxicity occurs 2 to 14 days after high-dose or prolonged low-dose oral MTX. This neurotoxicity manifests with seizures, aphasia, encephalopathy and stroke-like symptoms (Asato et al., 1992; Rubnitz et al., 1998). Excessive production of reactive oxygen species (ROS) has been implicated in MTX hepatotoxicity, nephrotoxicity, intestinal toxicity and cardiotoxicity (Abd El-Twab et al., 2016; El-Sheikh et al., 2016; Mahmoud et al., 2017a,b). MTX negatively impact the mitochondrial machinery and therefore generates excess ROS (Kolli et al., 2014). ROS can initiate peroxidation of the cell membranes and damage cellular macromolecules leading to cell death (Naik and Panda, 2007). In addition, inflammation has been reported to play a central role in MTX toxicity (Abd El-Twab et al., 2016; Mahmoud et al., 2017a,b). The nervous system has a high metabolic rate, high levels of polyunsaturated fatty acids and low levels of antioxidants; therefore, is vulnerable to damage by oxidative stress (Götz et al., 
1994; Barnham et al., 2004). Therefore, mitigating oxidative stress can prevent MTX toxicity to different body organs.

Berberine (BBR) is a natural isoquinoline alkaloid that can be isolated from Coptis chinensis (Teodoro et al., 2013). Previous work from our lab showed the protective effect of BBR against oxidative stress in animal models of diabetes (Mahmoud et al., 2017c) and hepatotoxicity (Germoush and Mahmoud, 2014; Mahmoud et al., 2014; Mahmoud et al., 2017b). Therefore, this study was designed to evaluate the protective effect of BBR against MTX-induced cerebral oxidative stress and inflammation in rats.

\section{MATERIALS AND METHODS}

\section{Chemicals}

MTX was supplied by Shanxi PUDE Pharmaceutical Company (Shanxi, China). BBR, reduced glutathione (GSH), 5,5'dithiobis-(2-nitrobenzoic acid), trichloroacetic acid, pyrogallol, 2(1-naphthylamino) ethylamine dihydrochloride, sulfanilamide, thiobarbituric acid and 1,1,3,3 tetramethoxypropane were purchased from Sigma (St. Louis, MO, USA). All other chemicals were of analytical grade and were supplied by standard suppliers.

\section{Experimental animals and treatments}

Twenty-four male Wistar rats weighing between 130$150 \mathrm{~g}$ were used in the present investigation. The animals were obtained from the National Institute of Ophthalmology (Giza, Egypt) and were housed in well-aerated standard cages at normal atmospheric temperature $\left(22 \pm 2{ }^{\circ} \mathrm{C}\right)$ and normal $12 \mathrm{~h}$ light/dark cycle. They were given a free access to a standard pellet diet and water ad libitum. All animal procedures were approved by the Institutional Ethics Committee of Beni-Suef University (Egypt).

The animals were divided into 4 groups, each comprising 6 rats $(\mathrm{N}=6)$ as following:

Group I (Control): rats received a single intraperitoneal (ip) injection of physiological saline and orally administered the vehicle $0.5 \%$ carboxymethyl cellulose (CMC) for 7 consecutive days.

Group II (MTX): rats received a single ip injection of MTX (20 $\mathrm{mg} / \mathrm{kg}$ ) dissolved in saline (Mahmoud et al., 2017a) and orally administered $0.5 \%$ CMC for 7 consecutive days.

Group III (MTX + $25 \mathrm{mg}$ BBR): rats received a single ip injection of MTX $(20 \mathrm{mg} / \mathrm{kg})$ and orally administered 25 $\mathrm{mg} / \mathrm{kg}$ BBR (Mahmoud et al., 2014) dissolved in $0.5 \%$ CMC for 7 consecutive days.

Group IV (MTX + $50 \mathrm{mg}$ BBR): rats received a single ip injection of MTX $(20 \mathrm{mg} / \mathrm{kg})$ and orally administered $50 \mathrm{mg} / \mathrm{kg}$ BBR (Mahmoud et al., 2014) dissolved in 0.5\% CMC for 7 consecutive days.

\section{Samples collection and preparation}

At the end of experiment, all rats were sacrificed under light ether anesthesia and the brain was quickly removed and rinsed with ice-cold saline. The cerebrum was dissected and kept frozen in liquid nitrogen. Frozen cerebrum samples $(10 \% \mathrm{w} / \mathrm{v})$ were homogenized in cold phosphate-buffered saline, centrifuged and the clear supernatant was collected and stored at $-80^{\circ} \mathrm{C}$ to assay malondialdehyde (MDA), nitric oxide (NO), GSH, superoxide dismutase (SOD), glutathione peroxidase (GPx) and glutathione-S-transferase (GST). Other samples from the cerebrum were collected on RNA later and kept at $-80^{\circ} \mathrm{C}$ for RNA isolation.

\section{Determination of lipid peroxidation, NO and antioxidant defenses}

Lipid peroxidation was determined in the cerebrum homogenate by assaying the level of MDA according to the method of Preuss et al (1998). NO level was assayed following the method of Grisham et al (1996), and GSH content was determined according to the method of Beutler et al (1963). SOD, GPx and GST were measured according to the methods of Marklund and Marklund (1974), Matkovics et al (1998) and Mannervik and Gutenberg (1981) respectively.

\section{Quantitative reverse transcriptase real time polymerase chain reaction (qRT-PCR)}

To determine the effect of BBR on MTX-induced inflammation, the gene expression levels of nuclear factor-kappaB $(\mathrm{NF}-\mathrm{\kappa B})$, inducible nitric oxide synthase (iNOS) and tumor necrosis factor alpha (TNF- $\alpha)$ were assayed using PCR as we previously reported (Mahmoud, 2014). Total RNA was isolated from the frozen cerebrum samples using Trizol reagent (Invitrogen, USA). Isolated RNA was treated with DNase I (Thermo Scientific, USA) and quantified at $260 \mathrm{~nm}$. RNA samples with A260/280 nm ratio of 1.8 or more were selected and the integrity was further confirmed using formaldehyde-agarose gel electrophoresis. Two $\mu \mathrm{g}$ RNA was reverse transcribed into first strand cDNA using RT kit (Thermo Scientific, USA). cDNA was amplified using SYBR green master mix (Thermo Scientific, USA) and the primer pairs listed in Table 1.

Table 1: Primers used in qRT-PCR.

\begin{tabular}{|c|c|c|c|}
\hline Gene & $\begin{array}{c}\text { GenBank } \\
\text { Accession } \\
\text { Number }\end{array}$ & Sequence $\left(5^{\prime}-3^{\prime}\right)$ & 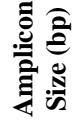 \\
\hline$N F-\kappa B$ & NM_199267.2 & $\begin{array}{c}\text { F: TCTCAGCTGCGACCCCG } \\
\text { R: TGGGCTGCTCAATGATCTCC }\end{array}$ & 122 \\
\hline iNOS & NM_012611.3 & $\begin{array}{l}\text { F: ATTCCCAGCCCAACAACACA } \\
\text { R: GCAGCTTGTCCAGGGATTCT }\end{array}$ & 112 \\
\hline$T N F-\alpha$ & $\begin{array}{c}\text { XM_008772775 } \\
.2\end{array}$ & $\begin{array}{l}\text { F: AAATGGGCTCCCTCTCATCAGTTC } \\
\text { R: TCTGCTTGGTGGTTTGCTACGAC }\end{array}$ & 111 \\
\hline$I L-1 \beta$ & NM_031512.2 & $\begin{array}{l}\text { F: GACTTCACCATGGAACCCGT } \\
\text { R: CAGGGAGGGAAACACACGTT }\end{array}$ & 200 \\
\hline B-Actin & NM_031144.3 & $\begin{array}{l}\text { F: AGGAGTACGATGAGTCCGGC } \\
\text { R: CGCAGCTCAGTAACAGTCCG }\end{array}$ & 71 \\
\hline
\end{tabular}

The qPCR reactions included 10 min initial denaturation at $95^{\circ} \mathrm{C}$ and 40 cycles each consists of $30 \mathrm{sec}$ denaturation at $95^{\circ} \mathrm{C}$, annealing for $60 \mathrm{sec}$ and extension at $72^{\circ} \mathrm{C}$ for $30 \mathrm{sec}$. The $2^{-\Delta \Delta \mathrm{C}}$ method (Livak and Schmittgen, 2011) was used to analyze the amplification data and results were normalized to $\beta$-actin. 


\section{Statistical analysis}

Statistical analysis was performed using GraphPad Prism 5 software (GraphPad Software, San Diego, CA). Results were expressed as mean \pm standard error of the mean (SEM) and all statistical comparisons were made by means of the one-way ANOVA test followed by Tukey's test post hoc analysis. A $P$ value $<0.05$ was considered significant.

\section{RESULTS}

\section{Berberine attenuates lipid peroxidation and NO generation in} the cerebrum of MTX-induced rats

MTX administration induced a significant $(\mathrm{P}<0.001)$ increase in the lipid peroxidation marker MDA in the cerebrum when compared with the control group (Fig. 1). Rats received 25 $\mathrm{mg} / \mathrm{kg}$ body weight berberine showed a significant $(\mathrm{P}<0.001)$ decrease in lipid peroxidation levels in the cerebrum. Similarly, MTX-induced rats treated with $50 \mathrm{mg} / \mathrm{kg}$ berberine exhibited significantly $(\mathrm{P}<0.001)$ declined cerebral lipid peroxidation levels as depicted in Figure 1.

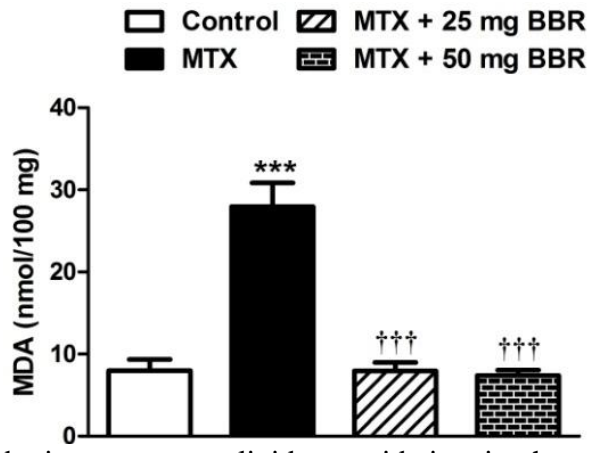

Fig. 1: Berberine attenuates lipid peroxidation in the cerebrum of MTX-induced rats. Data are Mean \pm SEM. Number of animals in each group is six. $* * * \mathrm{P}<0.001$ versus Control and $\uparrow \uparrow \uparrow \mathrm{P}<0.001$ versus MTX. MDA, malondialdehyde; BBR, berberine.

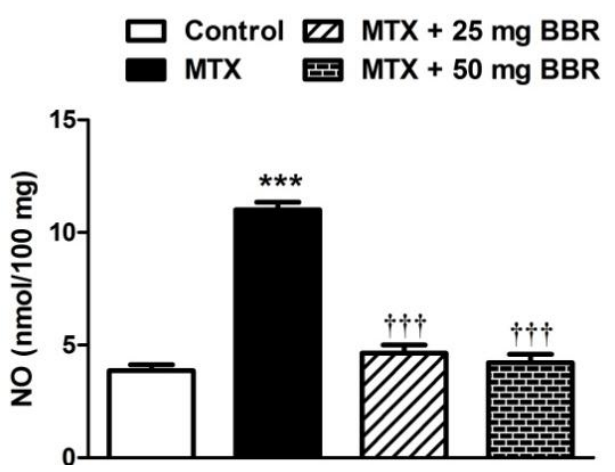

Fig. 2: Berberine reduces nitric oxide levels in the cerebrum of MTXinduced rats. Data are Mean \pm SEM. Number of animals in each group is six. ${ }^{* * *} \mathrm{P}<0.001$ versus Control and $\uparrow \uparrow \uparrow \mathrm{P}<0.001$ versus MTX. NO, nitric oxide; BBR, berberine.

MTX-induced rats showed a significant $(\mathrm{P}<0.001)$ increase in NO levels when compared with the control rats
(Fig. 2). Treatment with berberine at doses of 25 and $50 \mathrm{mg} / \mathrm{kg}$ body weight produced a significant $(\mathrm{P}<0.001)$ decrease in cerebral levels of NO in MTX-administered rats when compared with the untreated MTX-induced rats (Fig. 2).

\section{Berberine increases GSH content in the cerebrum of MTX- induced rats}

Analysis of the cerebral GSH content showed a significant $(\mathrm{P}<0.001)$ decrease in $\mathrm{MTX}$-induced rats when compared with the control group (Fig. 3). MTX-induced rats received $25 \mathrm{mg} / \mathrm{kg}$ body weight berberine showed a significant $(\mathrm{P}<0.001)$ increase in cerebral GSH content. Similarly, the higher berberine dose significantly $(\mathrm{P}<0.001)$ prevented MTX-induced GSH decline in the cerebrum of rats (Fig. 3).

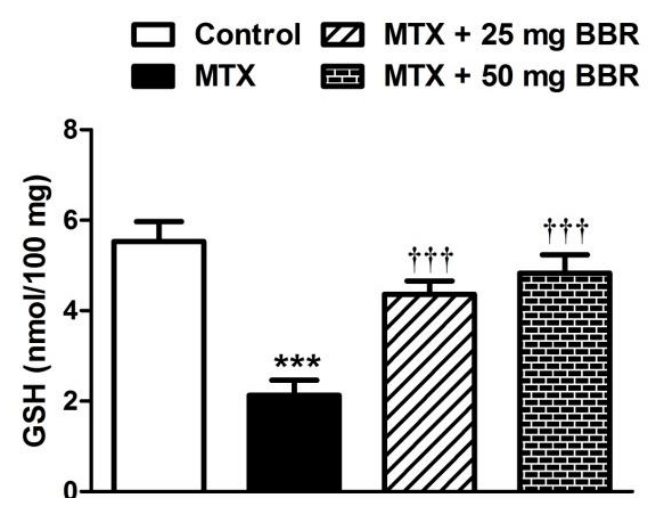

Fig. 3: Berberine increases reduced glutathione in the cerebrum of MTX-induced rats. Data are Mean \pm SEM. Number of animals in each group is six. ${ }^{* * *} \mathrm{P}<0.001$ versus Control and $\dagger \dagger \uparrow \mathrm{P}<0.001$ versus MTX. GSH, reduced glutathione; BBR, berberine.

Berberine enhances the activity of antioxidant enzymes in the cerebrum of MTX-induced rats

We determined the effect of berberine on the antioxidant defenses SOD, GPX and GST in the cerebrum of MTX-induced rats as represented in Figure 4.

MTX administration produced a significant $(\mathrm{P}<0.001)$ decline in the activity of cerebral SOD when compared with the control group of rats (Fig. 4A). MTX-induced rats received either 25 or $50 \mathrm{mg} / \mathrm{kg}$ body weight berberine showed a significant $(\mathrm{P}<0.001)$ increase in SOD activity.

GPx and GST showed a similar pattern where MTXinduced rats exhibited a significant $(\mathrm{P}<0.001)$ decrease in their activity in the cerebrum. On the other hand, MTX-induced rats received berbeine at doses of 25 and $50 \mathrm{mg} / \mathrm{kg}$ body weight showed significantly $(\mathrm{P}<0.001)$ increased activity of cerebral GPx (Fig. 4B) and GST (Fig. 4C). 


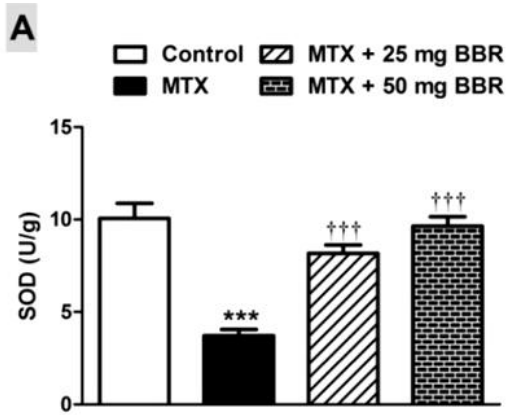

B

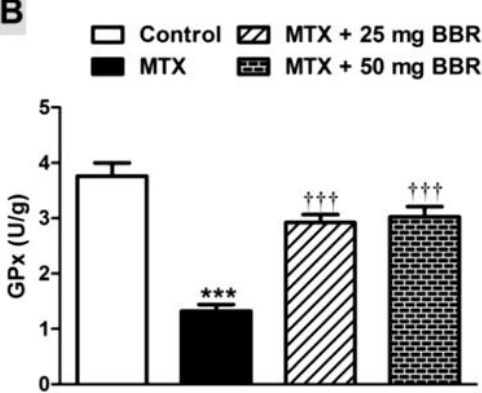

C

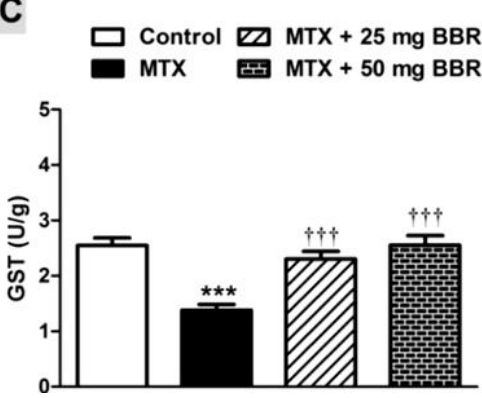

Fig. 4: Berberine enhances the activity of antioxidant enzymes in the cerebrum of MTX-induced rats. Data are Mean \pm SEM. Number of animals in each group is six. $* * * \mathrm{P}<0.001$ versus Control and $\uparrow \uparrow \uparrow \mathrm{P}<0.001$ versus MTX. SOD, superoxide dismutase; GPx, glutathione peroxidase; GST, glutathione-S-transferase; BBR, berberine.

\section{Berberine down-regulates NF- $\kappa \mathrm{B}$, iNOS and pro-inflammatory} cytokines in the cerebrum of MTX-induced rats

To evaluate the protective effect of berberine against MTX-induced inflammation in the cerebrum of rats, we determined the gene expression levels of NF- $\mathrm{B}$, iNOS, TNF- $\alpha$ and IL-1 $\beta$. Rats received MTX showed a significant $(\mathrm{P}<0.001)$ upregulation in $\mathrm{NF}-\kappa \mathrm{B}$ gene expression when compared with the control rats as depicted in Figure 5A. Similarly, iNOS gene expression was significantly $(\mathrm{P}<0.001)$ up-regulated in the cerebrum of MTX-induced rats when compared with the control group (Fig. 5B). MTX-induced rats treated with berberine at doses of 25 and $50 \mathrm{mg} / \mathrm{kg}$ body weight showed a significant $(\mathrm{P}<0.001)$ down-regulation of NF- $\mathrm{BB}$ (Fig. 5A) and iNOS (Fig. 5B) mRNA expression in the cerebrum. Gene expression of the proinflammatory cytokines TNF- $\alpha$ (Fig. 6A) and IL-1 $\beta$ (Fig. 6B) showed a significant $(\mathrm{P}<0.001)$ increase in their mRNA levels in the cerebrum of MTX-induced rats when compared with the control group. On the other hand, MTX-induced rats received 25 and $50 \mathrm{mg} / \mathrm{kg}$ body weight berberine exhibited a significant $(\mathrm{P}<0.001)$ down-regulation in mRNA expression levels of cerebral TNF- $\alpha$ and IL- $1 \beta$.

A

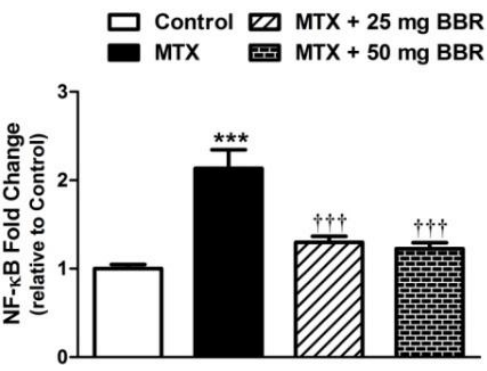

B

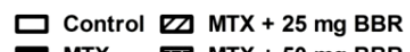

MTX 臣 MTX + $50 \mathrm{mg}$ BBR

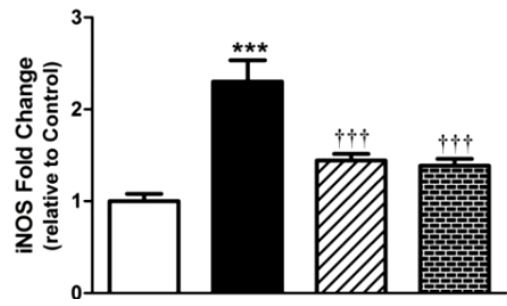

Fig. 5: Berberine down-regulates (A) nuclear factor-kappaB (NF- $\kappa \mathrm{B})$ and (B)inducible nitric oxide synthase (iNOS) expression in the cerebrum of MTX-induced rats. Data are Mean \pm SEM. Number of animals in each group is six. $* * * \mathrm{P}<0.001$ versus Control and $\dagger+\mathrm{P}<0.001$ versus MTX.BBR, berberine.

\section{A}

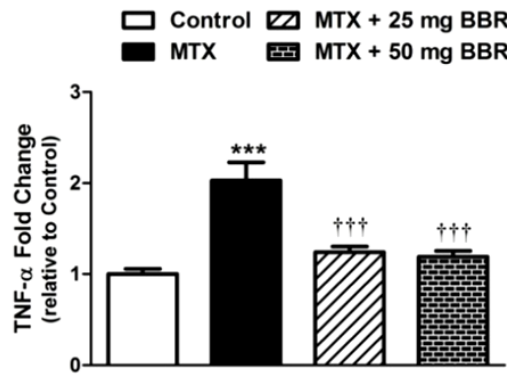

B

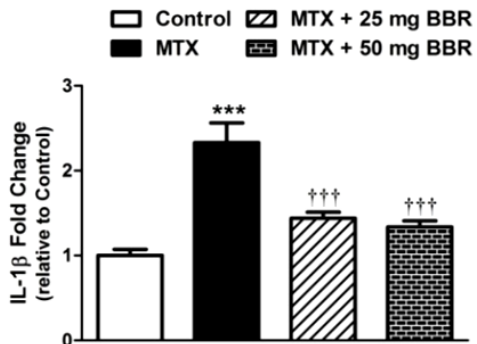

Fig. 6: Berberine down-regulates (A) tumor necrosis factor alpha $(\mathrm{TNF}-\alpha)$ and (B) interleukin-1beta (IL-1 $\beta)$ expression in the cerebrum of MTX-induced rats. Data are Mean \pm SEM. Number of animals in each group is six. ${ }^{* * *} \mathrm{P}<0.001$ versus Control and $\uparrow \dagger \uparrow \mathrm{P}<0.001$ versus MTX.BBR, berberine. 


\section{DISCUSSION}

The present study demonstrated the protective effect of the natural isoquinoline alkaloid berberine on MTX-induced neurotoxicity in rats. Berberine prevented oxidative/nitrosative stress, enhanced the antioxidant defenses and mitigated inflammation in the cerebrum of MTX-induced rats.

Oxidative stress and surplus production of ROS have been reported to play a central role in the toxicity of MTX (Abd El-Twab et al., 2016; El-Sheikh et al., 2016; Mahmoud et al., 2017a,b). The mechanism of excessive ROS generation by MTX involves its negative impact on the mitochondrial machinery (Kolli et al., 2014) and declined antioxidant defenses (Abd El-Twab et al., 2016; Mahmoud et al., 2017a,b). Possible mechanisms of excessive ROS generation involve the increased activity of purinecatabolizing enzymes adenosine deaminase (ADA) and xanthine oxidase $(\mathrm{XO})$. Impaired function of the mitochondrial membrane leads to impaired ATP metabolism with increased production of purine degradation products such as adenosine, inosine hypoxanthine and xanthine which are substrates for ADA and XO (Fadillioglu et al., 2003). ROS are well-known to elicit peroxidation of the membranous lipids, damage DNA and proteins, and subsequently leading to cell death (Naik and Panda, 2007). The nervous system is particularly vulnerable to oxidative damage because of its high metabolic rate, high levels of polyunsaturated fatty acids and low levels of antioxidants (Götz et al., 1994; Barnham et al., 2004).

Here, MTX-induced rats showed a significant increase in cerebral lipid peroxidation and NO levels. NO can react with superoxide radical to produce the versatile and potent oxidizing agent peroxynitrite which induces further cell damage (McKim et al., 2003). Interestingly, treatment with berberine markedly prevented MTX-induced lipid peroxidation and increased production of NO. In this context, berberine has been shown to protect against oxidative stress and memory impairment in a rat model of streptozotocin-induced diabetes (Bhutada et al., 2011). In rats with nonalcoholic steatohepatitis, Ghareeb et al. (2015) reported the ability of berberine to reduce oxidative stress and neurotoxicity. In this study, berberine decreased lipid peroxidation and increased the antioxidant defenses in the brain tissue of rats.In addition, the study of Siow et al. (2011) demonstrated that berberine quenches superoxide anions and NO, and exerts radical scavenging activity against the high reactive peroxynitrite and hydroxyl radicals. In cell based systems, berberine showed a potent inhibitory effect on ROS production (Hur et al., 2009) and prevented Nicotinamide adenine dinucleotide phosphate (NADPH) oxidase mediated superoxide production in lipopolysaccharide (LPS)-stimulated human monocyte-derived macrophages (Sarna et al., 2010). Furthermore, Srikanth et al. (2011) reported that berberine inhibits NO production LPS-stimulated murine macrophages by inhibiting iNOS expression. Furthermore, previous work from our lab demonstrated that berberine suppressed lipid peroxidation and reduced NO levels in rat models of drug-induced liver injury (Germoush and Mahmoud, 2014;
Mahmoud et al., 2014) and type 2 diabetes (Mahmoud et al., 2017c). MTX administration significantly reduced the antioxidants GSH, SOD, GPx and GST in the cerebrum of rats. These findings support our recent studies where we reported declined nonenzymatic and enzymatic antioxidants in MTX-induced rats (Mahmoud et al., 2017a,b). GSH is the most important cellular antioxidant for protecting against ROS and other oxidizing agents (Franco et al., 2007). GSH is the substrate for GPx that works with SOD, GST and other enzymes to protect the cell against the deleterious effects of ROS (Wei et al., 2011). The significant depletion of GSH induced by MTX administration might be the cause of reduced effectiveness of the antioxidant enzyme defense system, and therefore, sensitizing the cells to ROS (Babiak et al., 1998). A recent study by Moore et al. (2016) demonstrated downregulated SOD in different regions of the brain of methotrexatetreated rats. In addition, research from our laboratory showed a significant decline in GSH, SOD, GPx and GST in the kidney and liver of MTX-induced rats.

In the present study, MTX-induced rats received berberine exhibited significant amelioration in cerebral GSH, SOD, GPx and GST. Different studies have demonstrated the ameliorative effect of berberine on antioxidants in different tissue and organs in rats. We have previously reported that berberine enhances antioxidant defenses in liver of diabetic (Mahmoud et al., 2017c) and cyclophosphamide- (Germoush and Mahmoud, 2014), isoniazid/rifampicin- (Mahmoud et al., 2014) and MTXinduced rats (Mahmoud et al., 2017b). Therefore, we assume that the antioxidant efficacy of berberine plays a central role in its neuroprotective effect. In this context, we have recently shown the potential of antioxidants to protect against neurotoxicity in rats (Mahmoud and Abd El-Twab, 2017).

In addition to oxidative stress, inflammation is a central contributing factor in MTX-induced toxicity. In the present study, administration of MTX induced a significant up-regulation of NF$\kappa \mathrm{B}$ and iNOS. NF- $\kappa \mathrm{B}$ is a redox-sensitive transcription factor that can be activated as a result of increased ROS production (Matata and Galiñanes, 2002). Activated NF- $\mathrm{BB}$ elicits the transcription of genes of many inflammatory mediators suck as iNOS, TNF- $\alpha$ and IL-1 $\beta$. Here, the gene expression levels of iNOS, TNF- $\alpha$ and IL-1 $\beta$ were significantly up-regulated in the cerebrum of MTX-induced rats, demonstrating an inflammatory insult. In support of our findings, we have recently reported that the administration of MTX provoked inflammation in rats as evidenced by increased circulating levels of the pro-inflammatory cytokines (Abd ElTwab et al., 2016; Mahmoud et al., 2017a,b).

Berberine supplemented MTX-induced rats showed declined expression of NF- $\mathrm{B}$, iNOS, TNF- $\alpha$ and IL-1 $\beta$ in the cerebrum, pointing to a potent anti-inflammatory efficacy of berberine. Previous work from our laboratory showed that berberine prevents inflammation in diabetic (Mahmoud et al., 2017c) and cyclophosphamide- (Germoush and Mahmoud, 2014), isoniazid/rifampicin- (Mahmoud et al., 2014) and MTX-induced rats (Mahmoud et al., 2017b). The antioxidant and antiinflammatory mechanism of berberine involves activation of the 
nuclear factor (erythroid-derived 2)-like 2 (Nrf2) and peroxisome proliferator activated receptor gamma (PPAR $\gamma)$ as we previously demonstrated (Mahmoud et al., 2014, 2017b,c). Nrf2 induces the transcription of antioxidative genes, (Jaiswal, 2004), and has been implicated in the control of inflammation. Nrf2 activation is associated with down-regulation of NF- $\mathrm{BB}$ and iNOS (Mahmoud and Al Dera, 2015) and decreased production of pro-inflammatory cytokines (Mahmoud and Al Dera, 2015, Kamel et al., 2016; Mahmoud et al., 2017a,b,d,e). In addition, PPAR $\gamma$ activation modulates the expression of several antioxidant genes (Girnun et al., 2002, Chung et al., 2009) and induce anti-inflammatory responses (Yu et al., 2002).

In conclusion, the isoquinoline alkaloid berberine berberine prevented MTX-induced oxidative stress and inflammation in the cerebrum of rats. Berberine enhanced the nonenzymatic and enzymatic antioxidants in the cerebrum of MTXinduced rats. However, further studies are required to determine the exact neuroprotective mechanism of berberine.

\section{Financial support and sponsorship: Nil.}

Conflict of Interests: There are no conflicts of interest.

\section{REFERENCES}

Abd El-Twab SM, Hozayen WG, Hussein OE, Mahmoud AM. $18 \beta$-Glycyrrhetinic acid protects against methotrexate-induced kidney injury by up-regulating the Nrf2/ARE/HO-1 pathway and endogenous antioxidants. Ren Fail. 2016;38(9):1516-1527.

Asato R, Akiyama Y, Ito M, Kubota M, Okumura R, Miki Y, Konishi J, Mikawa H.Nuclear magnetic resonance abnormalities of the cerebral white matter in children with acute lymphoblastic leukemia and malignant lymphoma during and after central nervous system prophylactic treatment with intrathecal methotrexate. Cancer. 1992;70:1997-2004.

Ayad MW, El Naggar AA, El Naggar M. MTHFR C677T polymorphism: association with lymphoid neoplasm and effect on methotrexate therapy. Eur J Haematol. 2014;93(1):63-69.

Babiak RM, Campello AP, Carnieri EG,Olivera MB. Methotrexate: pentose cycle and oxidative stress. Cell Biochem Funct. 1998;16(4):283-293.

Barnham KJ, Masters CL, Bush AI.Neurodegenerative diseases and oxidative stress. Nat Rev Drug Discov. 2004;3:205-214.

Beutler E, Duron O, Kelly BM. Improved method for the determination of blood glutathione. J Lab Clin Mid. 1963;61:882-888.

Bhutada P1, Mundhada Y, Bansod K, Tawari S, Patil S, Dixit P, Umathe S, Mundhada D. Protection of cholinergic and antioxidant system contributes to the effect of berberine ameliorating memory dysfunction in rat model of streptozotocin-induced diabetes. Behav Brain Res. 2011;220(1):30-41.

Buizer AI, de Sonneville LM, van den Heuvel-Eibrink MM, Veerman AJ. Behavioral and educational limitations after chemotherapy for childhood acute lymphoblastic leukemia or Wilms tumor. Cancer. 2006;106:2067-2075.

Chung SS, Kim M, Youn BS, Lee NS, Park JW, Lee IK, Lee YS, Kim JB, Cho YM, Lee HK, Park KS. Glutathione peroxidase 3 mediates the antioxidant effect of peroxisome proliferator-activated receptor gamma in human skeletal muscle cells. Mol Cell Biol. 2009;29(1):20-30.

Cole PD, Beckwith KA, Vijayanathan V, Roychowdhury S, Smith AK, Kamen BA. Folate homeostasis in cerebrospinal fluid during therapy for acute lymphoblastic leukemia. Pediatr Neurol. 2009;40:34-41.
El-Sheikh AA, Morsy MA, Hamouda AH. Protective mechanisms of thymoquinone on methotrexate-induced intestinal toxicity in rats. Pharmacognosy Magazine. 2016;12(Suppl 1):S76-S81.

Fadillioglu E, Erdogan H, Iraz M, Yagmurca M. Effects of caffeic acid phenethyl ester against doxorubicin-induced neuronal oxidant injury. Neurosci Res Commun., 2003;33(2):132-138.

Franco R, Schoneveld OJ, Pappa A, Panayiotidis MI. The central role of glutathione in the pathophysiology of human diseases, Arch Physiol Biochem.2007;113(4-5):234-258.

Germoush MO and Mahmoud AM. Berberine mitigates cyclophosphamide-induced hepatotoxicity by modulating antioxidant status and inflammatory cytokines. $\mathrm{J}$ Cancer Res Clin Oncol. 2014;140:1103-1109.

Ghareeb DA, Khalil S, Hafez HS, Bajorath J, Ahmed HE, Sarhan E, ElwakeelE, El-Demellawy MA. Berberine reduces neurotoxicity related to nonalcoholic steatohepatitis in rats. Evid Based Complement Alternat Med. 2015;2015:361847.

Girnun GD, Domann FE, Moore SA, Robbins ME. Identification of a functional peroxisome proliferator-activated receptor response element in the rat catalase promoter. Mol Endocrinol. 2002;16(12):2793-2801.

Götz ME, Künig G, Riederer P, Youdim MB. Oxidative stress: free radical production in neural degeneration. Pharmacol Ther. 1994;63(1):37-122.

Grisham MB, Johnson GG, Lancaster JR Jr. Quantitation of nitrate and nitrite in extracellular fluids. Methods Enzymol. 1996;268:237246.

Hur JM, Hyun MS, Lim SY, Lee WY, Kim D. The combination of Berberine and irradiation enhances anti-cancer effects via activation of p38 MAPK pathway and ROS generation in human hepatoma cells. J Cell Biochem. 2009;107(5):955-964.

Inaba $\mathrm{H}$, Khan RB, Laningham FH, Crews KR, Pui CH, Daw NC. Clinical and radiological characteristics of methotrexate-induced acute encephalopathy in pediatric patients with cancer. Ann Oncol. 2008;19:178-184.

Jaiswal AK. Nrf2 signaling in coordinated activation of antioxidant gene expression. Free Radic Biol Med. 2004;36(10):11991207.

Kamel EM, Mahmoud AM, Ahmed SA, Lamsabhi AM. A phytochemical and computational study on flavonoids isolated from Trifoliumresupinatum L. and their novel hepatoprotective activity. Food Funct. 2016;7(4):2094-2106.

Kolli VK, Natarajan K, Isaac B, Selvakumar D, Abraham P. Mitochondrial dysfunction and respiratory chain defects in a rodent model of methotrexate-induced enteritis. Hum Exp Toxicol. 2014;33(10):10511065 .

Livak KJ and Schmittgen TD. Analysis of relative gene expression data using real-time quantitative PCR and the 2(-Delta Delta C(T)) Method. Methods. 2001;25(4):402-408.

Mahmoud AM and Abd El-Twab SM. Caffeic acid phenethyl ester protects the brain against hexavalent chromium toxicity by enhancing endogenous antioxidants and modulating the JAK/STAT signaling pathway. Biomed Pharmacother. 2017;91:303-311.

Mahmoud AM and Al Dera HS. 18ß-Glycyrrhetinic acid exerts protective effects against cyclophosphamide-induced hepatotoxicity: potential role of PPAR $\gamma$ and Nrf2 upregulation. Genes Nutr. 2015;10(6):41.

Mahmoud AM, Abdel-Rahman MM, Bastawy NA, Eissa HM. Modulatory effect of berberine on adipose tissue PPARg, adipocytokines and oxidative stress in high fat diet/ streptozotocin-induced diabetic rats. J Appl Pharm Sci. 2017c;7:1-10.

Mahmoud AM, Alqahtani S, Othman SI, Germoush MO, Hussein OE, Al-Basher G, Khim JS, Al-Qaraawi MA, Al-Harbi HM, Fadel A, Allam AA. Commiphoramolmol modulates glutamate-nitric oxide-cGMP and Nrf2/ARE/HO-1 pathways and attenuates oxidative stress and hematological alterations in hyperammonemic rats. Oxid Med Cell Longev. 2017e;2017:7369671. 
Mahmoud AM, Germoush MO, Alotaibi MF, Hussein OE. Possible involvement of Nrf2 and PPAR $\gamma$ up-regulation in the protective effect of umbelliferone against cyclophosphamide-induced hepatotoxicity. Biomed Pharmacother. 2017f;86:297-306.

Mahmoud AM, Germoush MO, Soliman AS. Berberine attenuates isoniazid-induced hepatotoxicity by modulating peroxisome proliferator-activated receptory g, oxidative stress and inflammation. Int J Pharmacol. 2014;10:451-460.

Mahmoud AM, Hozayen WG, Ramadan SM. Berberine ameliorates methotrexate-induced liver injury by activating Nrf2/HO-1 pathway and PPAR $\gamma$, and suppressing oxidative stress and apoptosis in rats. Biomed Pharmacother. 2017b;94:280-291.

Mahmoud AM, Hussein OE, Hozayen WG, Abd El-Twab SM. Methotrexate hepatotoxicity is associated with oxidative stress, and downregulation of PPARgamma and Nrf2: Protective effect of 18betaGlycyrrhetinic acid. Chem Biol Interact. 2017a; 270:59-72.

Mahmoud AM, Zaki AR, Hassan ME, Mostafa-Hedeab G. Commiphoramolmol resin attenuates diethylnitrosamine/phenobarbitalinduced hepatocarcinogenesis by modulating oxidative stress, inflammation, angiogenesis and Nrf2/ARE/HO-1 signaling. Chem Biol Interact. 2017d;270:41-50.

Mahmoud AM. Hesperidin protects against cyclophosphamideinduced hepatotoxicity by upregulation of PPAR $\gamma$ and abrogation of oxidative stress and inflammation. Can $J$ Physiol Pharmacol. 2014;92(9):717-724.

Mannervik B andGuthenberg C. Glutathione transferase (human placenta). Methods Enzymol. 1981;77:231-235.

Marklund SL andMarklund G. Involvement of the superoxide anion radical in the autoxidation of pyrogallol and a convenient assay for superoxide dismutase. Eur J Biochem. 1974;47:469-474.

Matata BM and Galiñanes M. Peroxynitrite is an essential component of cytokines production mechanism in human monocytes through modulation of nuclear factor-kappa B DNA binding activity. J Biol. Chem.2002;277:2330-2335.

Matkovics B, Szabo L, Varga IS. Determination of enzyme activities in lipid peroxidation and glutathione pathways (in Hungarian). Lab Diagn. 1998;15:248-249.

McKim SE, Gäbele E, Isayama F, Lambert JC, Tucker LM, Wheeler MD, Connor HD, Mason RP, Doll MA, Hein DW, Arteel GE. Inducible nitric oxide synthase is required in alcohol-induced liver injury: studies with knockout mice. Gastroenterology. 2003;125:1834-1844.

Moore IM, Merkle CJ, Byrne H, Ross A, Hawkins AM, Ameli SS, Montgomery DW. Effects of intraventricular methotrexate on neuronal injury and gene expression in a rat model: findings from an exploratory study. Biol Res Nurs. 2016;18(5):505-514.

Naik SR and Panda VS. Antioxidant and hepatoprotective effects of Ginkgo biloba phytosomes in carbon tetrachloride-induced liver injury in rodents. Liver Int. 2007;27(3):393-399.

Preuss HG, Jarrell ST, Scheckenbach R, Lieberman S, Anderson RA. Comparative effect of chromium vanadium and gymnemasylvestre on sugar-induced blood pressure elevation in SHR. J Am Coll Nutr. 1998;17:116-123.
Roenigk HH Jr, Auerbach R, Maibach H, Weinstein G, Lebwohl M. Methotrexate in psoriasis: consensus conference. J Am AcadDermatol. 1998;38(3):478-485.

Rubnitz JE, Relling MV, Harrison PL, Sandlund JT, Ribeiro RC, Rivera GK, Thompson SJ, Evans WE, Pui CH.Transient encephalopathy following high-dose methotrexate treatment in childhood acute lymphoblastic leukemia. Leukemia. 1998;12:1176-1181.

Sakthiswary R and Suresh E. Methotrexate in systemic lupus erythematosus: a systematic review of its efficacy. Lupus. 2014;23(3):225235.

Sarna LK, Wu N, Hwang SY, Siow YL, O K. Berberine inhibits NADPH oxidase mediated superoxide anion production in macrophages. Can J PhysiolPharmacol. 2010;88(3):369-378.

Siow YL, Sarna L. OK. Redox regulation in health and disease - therapeutic potential of berberine. Food Res Int. 2011;44(8):2409-2417.

Srikanth V, Maczurek A, Phan T, Steele M, Westcott B, Juskiw D, Münch G. Advanced glycation endproducts and their receptor RAGE in Alzheimer's disease, Neurobiol Aging. 2011;32(5):763-777.

Teodoro JS, Duarte FV, Gomes AP, Varela AT, Peixoto FM, Rolo AP, Palmeira CM. Berberine reverts hepatic mitochondrial dysfunction in high-fat fed rats: a possible role for SirT3 activation. Mitochondrion. 2013;13:637-646.

Vezmar S, Schüsseler P, Becker A, Bode U, Jaehde U. Methotrexate-associated alterations of the folate and methyl-transfer pathway in the CSF of ALL patients with and without symptoms of neurotoxicity. Pediatr Blood Cancer. 2009;52:26-32.

Wei XJ, Hu TJ, Chen JR, Wei YY.Inhibitory effect of carboxymethylpachymaran on cyclophosphamide-induced oxidative stress in mice. Int J Biol Macromol.2011;49(4):801-805.

Yu Y, Correll P, Heuvel JV. Conjugated linoleic acid decreases production of pro-inflammatory products in macrophages: evidence for a PPAR $\gamma$-dependent mechanism. Biochim Biophys Acta. 2002;1581(3):8999.

Zhu H, Deng FY, Mo XB, Qiu YH, Lei SF. Pharmacogenetics and pharmacogenomics for rheumatoid arthritis responsiveness to methotrexate treatment: the 2013 update. Pharmacogenomics 2014;15(4):551-566.

\section{How to cite this article:}

Hozayen WG, Ramadan SM, Fadel A, Mahmoud AM. Berberine mitigates methotrexate-induced oxidative stress and inflammation in the cerebrum of rats. J App Pharm Sci, 2017; 7 (11): 043-049. 